\title{
Medicare's Evolution: National Pharmacare and Shared Leadership
}

Joanna Nemis-White, Emily Torr, John Aylen, Amédé Gogovor, Lesli Martin, Jonathan Mitchell, Nicole MacPherson and Terrence Montague

\begin{abstract}
Repeated Health Care in Canada ( $\mathrm{HClC}$ ) surveys over the past two decades have consistently reported that the adult public and clinical and administrative health professionals consider medicare to be successful in terms of quality of care, despite a growing concern that timely access to care remains challenging. These key stakeholders have also recently signalled that major change strategies are likely necessary for continuing success. In the 2018 survey, both the public and professionals ranked highest the creation of a national comprehensive pharmacare plan, entirely funded by the federal government, or with federal funding for those not currently covered by existing pharmaceutical plans. The majority of the public and health professionals in 2018 were also remarkably concordant regarding preferred leadership for designing, instituting and managing a national pharmacare program. The public's priority, supported by $50 \%$ of the adult population, was shared leadership involving governments, medical academia and the pharmaceutical/ biotech industries, followed by government leadership at $33 \%$. Among professionals, preference for shared leadership averaged $60 \%$ and governmental leadership averaged $33 \%$. Based on these data, restriction of pharmacare's leadership exclusively to any single stakeholder raises concern of a critical lack of support for success. A coalition of governments, research hospitals/health authorities and
\end{abstract}

the pharmaceutical/biotech industry - the highest-ranked candidates as potential leaders - would likely provide the best chance to garner the majority of public support and enhance the chances of success in the short and long terms. In summary, the addition of universal pharmacare to medicare's existing healthcare portfolios is an attractive strategy to advance Canadian healthcare and outcomes. The federal government has taken the initial step. Recruitment of additional leaders sharing aspiration, inspiration and experience to optimize pharmacare's development and measure its outcomes is needed. Things can be better.

\section{Introduction}

The Health Care in Canada (HCIC) partnership and surveys were initiated two decades ago to measure and report the opinions of the Canadian adult public and healthcare professionals regarding key challenges, operational performance and future opportunities surrounding Canada's healthcare system (Montague et al. 2016, 2017a, 2018; Nemis-White et al. 2014). The overarching HCIC survey goals remain the acquisition and propagation of reliable data to inform and facilitate stakeholder decision-making for improved healthcare policy, practices and outcomes.

The HCIC survey implementation, data collection and initial analyses are advised and facilitated by Pollara Strategic 
Insights. The knowledge translation activities and impact are assessed via a robust evaluation strategy, including tracking of requests for $\mathrm{HCIC}$ data use, Web metric citations of HCIC publications, partner feedback, media impressions and data-use roster requests (Figure 1).

\section{HCIC Partners, Data Acquisition and Knowledge Translation}

Current HCIC survey members include the Canadian Cancer Society, Canadian Home Care Association, Canadian Hospice Palliative Care Association, Canadian Medical Association, Canadian Nurses Association, Canadian Pharmacists Association, Constance Lethbridge Rehabilitation Centre/ Centre for Interdisciplinary Research in Rehabilitation, McGill University, Health Charities Coalition of Canada, HealthCare $C A N$, Innovative Medicines Canada, Institute of Health Economics, Studer Group Canada, Merck Canada, Strive Health Management Consulting and CareNet Health Management Consulting. Pollara Strategic Insights provided professional leadership regarding question formatting, data collection and collation for all surveys in collaboration with the general HCIC membership and the Knowledge Translation Committee.
Data sources for all HCIC surveys have been representative samples of the Canadian adult public and a broad spectrum of clinical and administrative health professionals. For the 2016 and 2018 surveys (HCIC 2016, 2018), the public sample sizes were 1,500 and the professional samples averaged 100 for each professional group of doctors, nurses, pharmacists, administrators and other professionals (e.g., dietitians, occupational therapists, physical therapists, psychologists and social workers). Probability samples of these sizes provide an estimated $\pm 2.5 \%$ margin of error for the public responses and $\pm 9.8 \%$ for each professional group (excluding "other professionals," which does not have an estimated margin of error).

Translation of the knowledge gained from various HCIC surveys has been via peer-reviewed publications, live presentation webinars and HCIC website postings (Ahmed et al. 2009; Gogovor et al. 2016; Montague et al. 2015a, 2015b, 2016, 2017a, 2017b; Nemis-White et al. 2014).

\section{Medicare's Current Reality}

Despite persistently strong belief in the value of medicare and the provision of quality care provided to patients, the majority of the Canadian adult population and health professionals have also signalled in recent HCIC surveys that major changes may be necessary for medicare's continuing success and

FIGURE 1.

Overview of the HCIC surveys' logic model of data acquisition and knowledge translation outcomes

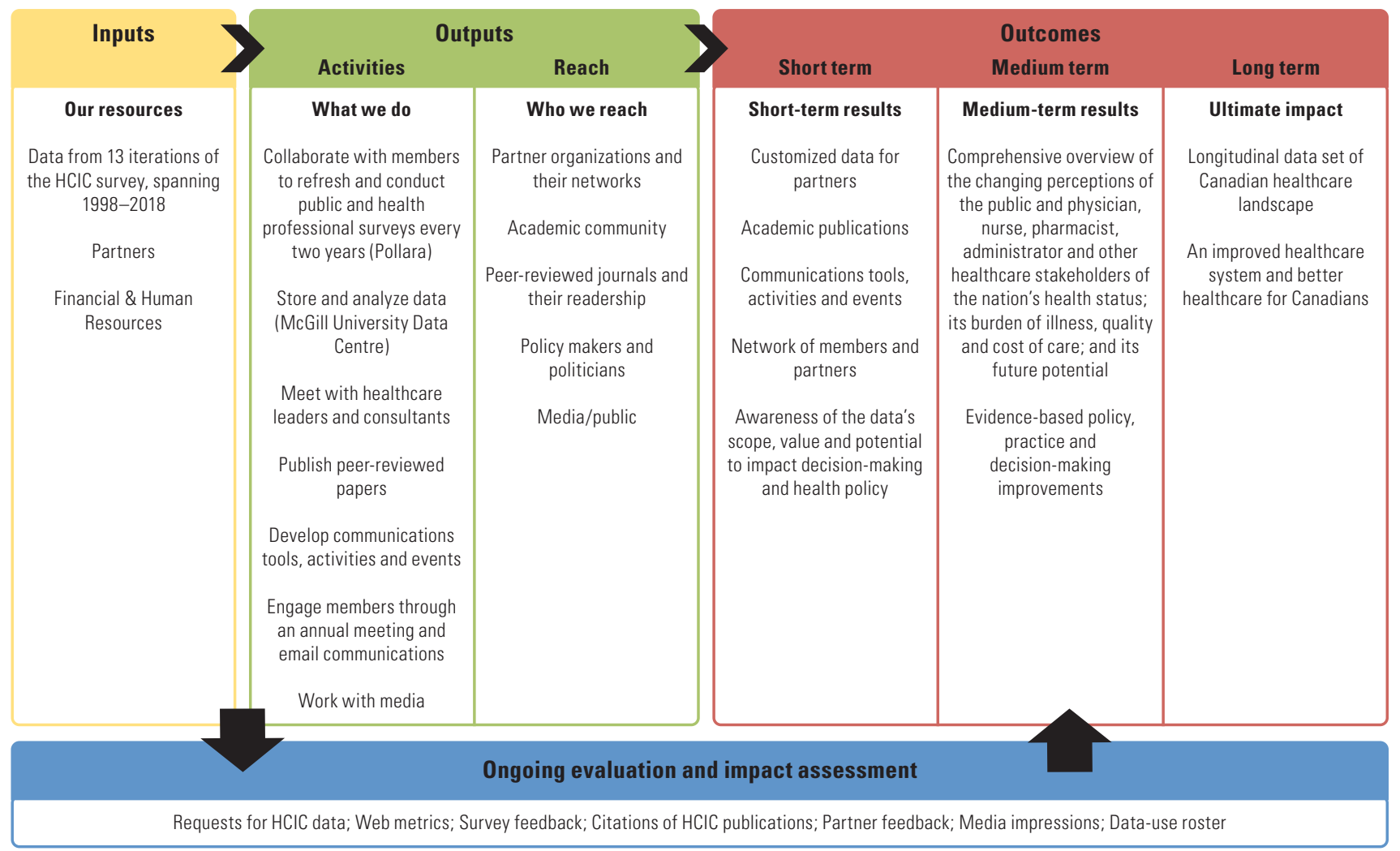

$\mathrm{HCIC}=$ Health Care in Canada 
improvement (Montague et al. 2015a, 2016, 2018). In terms of specific innovation to improve future medicare performance, the development of a national, publicly funded pharmacare plan, that is, a system of health insurance coverage that provides people with access to necessary prescription drugs, has recently received strong support among the public and health professionals (Government of Canada 2018). However, the exact idea of what pharmacare looks like for Canadians can be interpreted differently by different constituencies (Canadian Pharmacists Association n.d.).

In the 2016 HCIC survey, $47 \%$ of professionals and 39\% of the public indicated a preference for a national pharmacare program delivered through a single national plan funded by federally collected taxes. As their second option, $19 \%$ of professionals and $17 \%$ of the public suggested the development of more plans operated by private insurance companies, supplemented by federal funding for persons with high out-of-pocket drug costs (HCIC 2016).

In the $2018 \mathrm{HCIC}$ survey, the top-ranked choices for provision of a national prescription drug program were similar: a program with the federal government filling in gaps for drug costs not covered by other sources and/or a single national pharmacare plan funded and operated by the federal government (Figure 2). Interestingly, regional or provincial plans were not strongly supported in either survey (Figure 2).

As Canada grapples with our approach, the experience of other countries shows that no one system is favoured - many models exist, each with unique benefits and opportunities for improvement. For example, Australia and the UK cover medications through a national program funded through taxes, whereas other countries (Germany, the Netherlands) have mandatory private insurance systems regulated by the national government
(Government of Canada 2018). In some countries, patients may pay a small fee for each prescription, whereas in other systems, employer insurance plans for employees and their dependents support drug coverage. Certainly, "one size does not fit all."

\section{Bringing Canada's Healthcare Priorities to Reality: Leadership}

In multidisciplinary human endeavours, with very basic and competing interests, it is fair to say that leadership is a critical success factor. The complex arena of contemporary and future healthcare in Canada is no exception. Rather, there is a need for a practical convergence of professional, corporate and political interests to achieve evidence-based, patient-centred care with measured outcomes, as well as capable, visionary and perhaps even altruistic leadership.

As outlined above, recent HCIC survey measurements reveal remarkable symmetry among the general public and health professionals in identifying the priority of universal pharmacare as a key component of medicare's future. Moreover, they share a common opinion on who is best suited to successfully lead the institution of an effective national pharmacare strategy. In both the 2016 and $2018 \mathrm{HCIC}$ surveys, the top three individually specified leaders for introducing health system innovation were identified as the pharmaceutical/biotech industries, research hospitals/health administrations and governments. However, a notable difference between the 2016 and 2018 surveys was the introduction of a shared-leadership option in the 2018 survey.

The 2018 HCIC leadership preferences for the development of a successful pharmacare plan are detailed in Figure 3. Interestingly, both the adult public's (50\%) and health professionals' (68\%) first-choice leadership preference was a shared leadership model.

\title{
FIGURE 2.
}

\begin{abstract}
Canadians' and health professionals' opinions from the 2018 Health Care in Canada survey when asked "Which one of the following three options would you choose as the best approach for ensuring that all Canadians have access to prescription medications?"
\end{abstract}

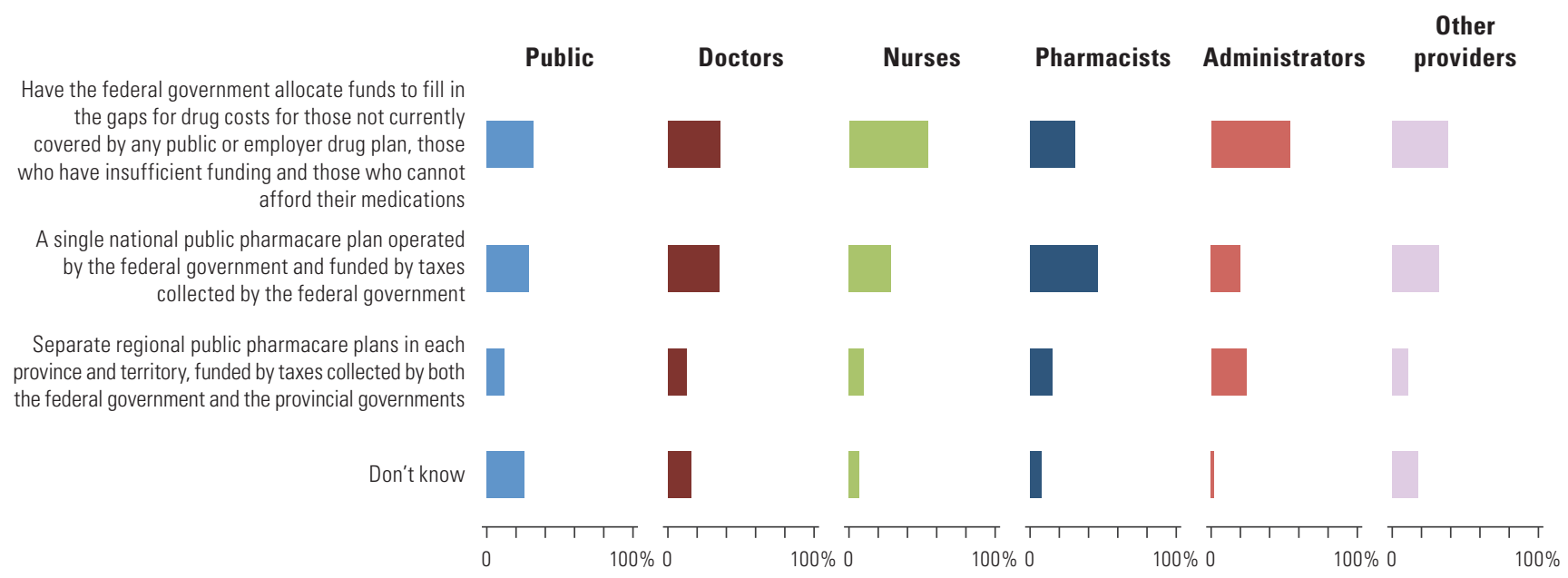


FIGURE 3.

Canadians' and health professionals' rankings for leadership when asked in 2018, “Who should lead the development of a pharmacare program for Canada?"

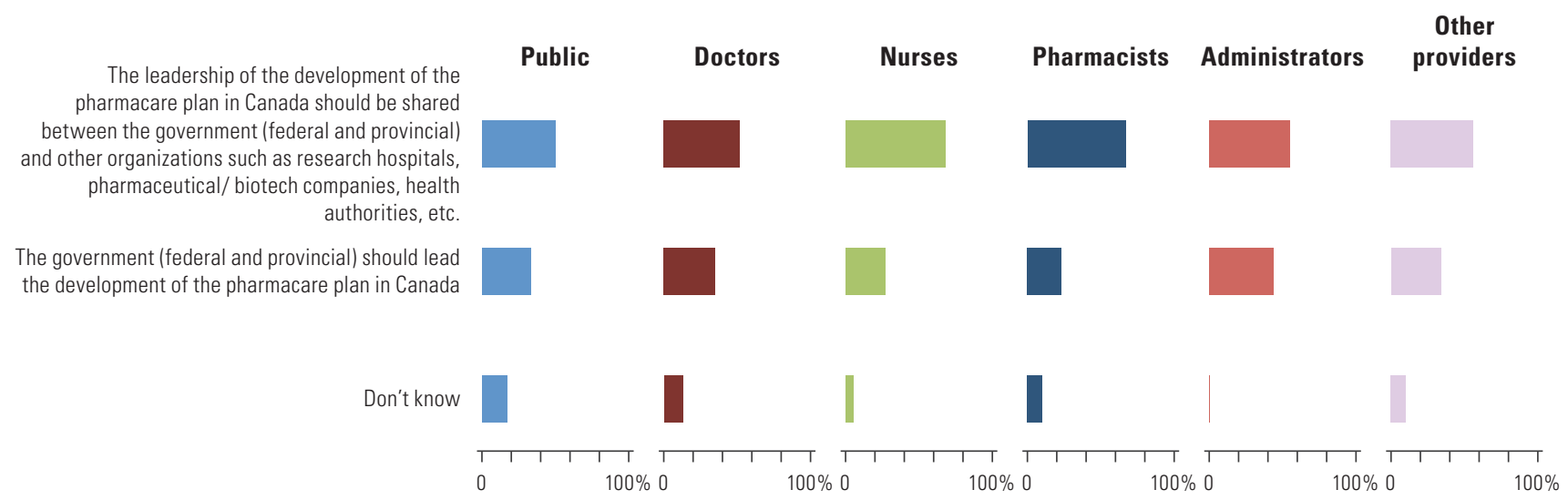

\section{Leadership for Success}

There are multiple definitions of leadership, but one that is often quoted in various areas of endeavour was originally expressed by US Army General Norman Schwarzkopf. Based on his wide experience in the military and politics, he felt the essence of leadership is the ability to effectively stimulate someone to do something they might otherwise not do.

The dominant contemporary leadership model in many, or most, business or academic endeavours is hierarchal, where vision, inspiration and support to lead are often attributed to a single person. Characteristics commonly associated with success in the single-leader model include knowing one's self/ profession/business and communicating, communicating, communicating. Exceptional individual leaders also seem to have a sense of selflessness or courage. They do not order subordinates or companions to go in harm's way. They go first and others follow. They are rare.

Shared leadership, despite success as a model dating from the innovative governmental and military achievements of the Roman Republic, is not widely understood or embraced today. However, success has been demonstrated, particularly in contemporary educational and some healthcare settings (Jackson 2000; Kocolowski 2010; Willcocks 2018).

A shared leadership model has been used in New Zealand since 1993 (New Zealand Government 2018). Their Pharmaceutical Management Agency (PHARMAC) is a government body that makes decisions regarding which medications and treatments will be publicly funded in New Zealand. The Pharmacology and Therapeutics Advisory Committee, comprising practising physicians, advises PHARMAC, whereas a Consumer Advocacy Committee provides patient insight. This type of shared leadership has led to what has been perceived by some as a largely successful pharmacare program in that country. However, the program itself has received much criticism for its anticompetitive strategies, erosion of intellectual property, limited access to clinically effective and innovative medicines and system supply challenges (Cummings et al. 2010).

The recent HCIC data suggest that shared leadership should be seriously considered to advance Canada's universal medicare evolution toward inclusion of a universal pharmacare asset. The reasons are twofold: leading and managing modern professions and businesses, particularly healthcare, are increasingly complex and require a balance of skills and knowledge. The HCIC data indicate that a majority of the public and healthcare professionals recognize these challenges. Consequently, they do not fully support any single governmental, institutional or corporate entity as having the necessary leadership skills to effectively achieve success in implementing pharmacare. The underwhelming support for single pharmacare leadership going forward suggests a risk of failure from the lack of the critical support needed to create and deliver a successful program over the longer term.

In contrast, shared, or team, leadership - specifically involving government(s), research hospitals/health authorities and the pharmaceutical/biotech industries - may enable a very different future for healthcare, one that provides leadership supported by all the key stakeholders. Because Canadian health professionals and the public have no clear opinion on how exactly to proceed with pharmacare - fill in the gaps versus a national federally funded/operated program - shared leadership will be essential to move forward. Team leadership of pharmacare can also be viewed as a call to arms, and a logical extension to, patient-centred clinical care, where decisions are made in a team including patients and professional providers (Montague et al. 2017b). Although barriers and challenges to shared leadership exist, it is a trail worth exploring and measuring (Jackson 2000; Kocolowski 2010; Willcocks 2018). Things can be better. HQ 


\section{References}

Ahmed, S., A. Gogovor, E. Berman, M. Miloff, B. Burnand, M. Krelenbaum et al. 2009. "Changing Healthcare: Stakeholder Perceptions of the Burden of Chronic Disease and the Value of Teams, Measurements and Communication." Healthcare Quarterly 12(2): e1-13. doi:10.12927/hcq.2009.20598.

Canadian Pharmacists Association. n.d. Pharmacare. Retrieved February 8, 2019. <https://www.pharmacists.ca/advocacy/pharmacare-20/>.

Cummings, J., N. Mays and J. Daubé. 2010. "How New Zealand Has Contained Expenditure on Drugs.” BMJ340: 1224-27. doi:10.1136/ bmj.c2441.

Gogovor, A., S. Ahmed, J. Nemis-White, E. Torr, J. Aylen, L. Marshall et al. 2016. "e-Technology-Facilitated Patient Care: Complementary and Contrasting Views of the Canadian Pubic and Health Professionals." Retrieved September 21, 2018. <https://mcgill.ca/hcic-sssc/files/ hcic-sssc/hcic_technology_facilitated_health_care_nov_2_2016.pdf>.

Government of Canada. 2018. Towards Implementation of National Pharmacare: Discussion Paper. Retrieved February 21, 2019. <https://www.canada.ca/content/dam/hc-sc/documents/corporate/ publications/council_on_pharmacare_EN.PDF>.

Health Care in Canada (HCIC) Survey. 2016. 2016 Results: Looking Forward. Retrieved September 19, 2018. <https://mcgill.ca/hcic-ssscl files/hcic-sssc/hcic_2016_results_10-looking_forward.pdf>.

Health Care in Canada (HCIC) Survey. 2018. Results of the 2018 Health Care in Canada Survey: A National Survey of Health Care Providers, Managers and the Public. Retrieved October 28, 2018. <https://www. mcgill.ca/hcic-sssc/hcic-surveys/2018>.

Jackson, S.G. 2000. "A Qualitative Evaluation of Shared Leadership Barriers, Drivers and Recommendations." Journal of Management in Medicine 14(3/4): 166-78. doi:10.1108/02689230010359174.

Kocolowski, M.D. 2010. "Shared Leadership: Is It Time for a Change?" Emerging Leadership Journeys 3(1): 22-32.

Montague, T., A. Gogovor, S. Ahmed, E. Torr, J. Aylen, L. Marshall, et al. 2015a. "Contributions and Challenges of Non-Professional Patient Care: A Key Component of Contemporary Canadian Healthcare." Healthcare Quarterly 18(3): 18-22. doi:10.12927/hcq.2015.24436.

Montague, T., J. Nemis-White, L. Marshall, A. Gogovor, E. Torr and S. Ahmed for the Health Care in Canada Survey Members. 2015b. "Recent Health Care Trends in Canada: Perceptions of Quality, Access and Affordability; and, Priorities for Improvement, 1998-2014." Retrieved September 19, 2018. <https:/www.mcgill.ca/hcic-sssc/files/ hcic-sssc/hcic_trends_quality_access_affordability_2015.pdf >.

Montague, T., A. Gogovor, L. Marshall, B. Cochrane, S. Ahmed, E. Torr, et al. 2016. "Searching for Best Direction in Healthcare: Distilling Opportunities, Priorities and Responsibilities." Healthcare Quarterly 19(3): 44-49. doi:10.12927/hcq.2016.24867.

Montague, T., A. Gogovor, J. Aylen, L. Ashey, S. Ahmed, L. Martin et al. 2017a. "Patient-Centred Care in Canada: Key Components and the Path Forward." Healthcare Quarterly 20(1): 50-56. doi:10.12927/ hcq.2017.25136.
Montague, T., J. Nemis-White, J. Aylen, S. Ahmed, S. Baxter, L. Martin, et al. 2017b. "Public and Professional Insights on End-ofLife Care: Results of the 2016 Health Care in Canada Survey." Healthcare Quarterly 20(2): 18-22. doi:10.12927/hcq.2017.25222.

Montague, T., B. Cochrane, A. Gogovor, J. Aylen, L. Martin and J. Nemis-White. 2018. "Healthcare in Canada: Choices Going Forward." Healthcare Quarterly 21(1): 13-18. doi:10.12927/ hcq.2018.25522.

Nemis-White, J., E. Torr, A. Gogovor, L. Marshall, S. Ahmed, J. Aylen et al. 2014. "Stakeholder Surveys of Canadian Healthcare Performance: What Are They Telling Us? Who Should Be Listening? Who Should Be Acting, and How?" Healthcare Quarterly 17(4): 22-27. doi:10.12927/ hcq.2015.24113.

New Zealand Government. 2018. Your Guide to PHARMAC. Retrieved February 8, 2019. <https:/www.pharmac.govt.nz/about/your-guideto-pharmac/>.

Willcocks, S.G. 2018. "Exploring Team Working and Shared Leadership in Multi-Disciplinary Cancer Care." Leadership in Health Services 31(1): 98-109. doi:10.1108/LHS-02-2017-0011.

\section{About the Authors}

Joanna Nemis-White, BSc, PMP, is the principal at Strive Health Management Consulting Inc., Halifax, NS.

Emily Torr, BPHE, MSc, is a consultant in healthcare research and knowledge translation, Toronto, ON.

John Aylen, MA, is the president of John Aylen Communications, Montréal, QC.

Amédé Gogovor, DVM, MSc, $\mathrm{PhD}$, is a research assistant at McGill University and postdoctoral fellow at Laval University, QC.

Lesli Martin, BA, is the vice-president of public affairs at Pollara Strategic Insights, Toronto, ON.

Jonathan Mitchell, MSc, CHE, FISQua, is the vice-president of research and policy at HealthCareCAN, Ottawa, ON.

Nicole MacPherson, BA, BScAHN, PDt, is a research assistant at Strive Health Management Consulting Inc., Halifax, NS.

Terrence Montague, CM, CD, MD, is the principal at CareNet Health Management Consulting and an adjunct professor of medicine at the University of Alberta, Edmonton, AB. 